\title{
Relation between gastric acid output, Helicobacter pylori, and gastric metaplasia in the duodenal bulb
}

\author{
A W Harris, P A Gummett, M M Walker, J J Misiewicz, J H Baron
}

\begin{abstract}
Background-Factors that determine gastric metaplasia in the duodenal bulb are ill defined. It is more common and extensive in the presence of high acid output and possibly in the presence of Helicobacter pylori. However, no quantitative relation between acid output and the extent of gastric metaplasia has been demonstrated and its relation to $H$ pylori is uncertain.
\end{abstract}

Aim-To determine the relation between $H$ pylori infection and acid output and the presence and extent of gastric metaplasia in the duodenal bulb.

Subjects-H pylori positive and negative patients with duodenal ulcer and healthy controls were studied.

Methods-Quadrantic duodenal bulb biopsy specimens were taken and the presence and extent of gastric metaplasia determined using a computer enhanced image intensifier. Basal and stimulated acid outputs were measured.

Results-Gastric metaplasia was significantly $(p<0.05)$ more common and significantly $(p<0.05)$ greater in extent in patients with duodenal ulcer than in controls. Neither the prevalence or extent of gastric metaplasia was affected by $H$ pylori status. There were significant $(p<0 \cdot 01)$ direct correlations between acid output and extent of gastric metaplasia.

Conclusions-Prevalence and extent of gastric metaplasia are not related to $H$ pylori in controls, or in patients with duodenal ulcer. Rather, high acid response to gastrin may be more important.

(Gut 1996; 39: 513-520)

Keywords: gastric acid output, Helicobacter pylori, gastric metaplasia, duodenal bulb.

Parkside Helicobacter Study Group, Central Middlesex and St Mary's Hospitals, London

A W Harris

P A Gummett

M M Walker

J J Misiewicz

J H Baron

Correspondence to:

Dr A Harris,

Department of

Gastroenterology

and Nutrition

Central Middlesex Hospital,

London NW10 7NS.

Accepted for publication 9 May 1996
Gastric metaplasia in the duodenal bulb (DGM) is defined as the change from intestinal to gastric type epithelium. In animal models DGM develops in the presence of duodenal injury and acid, possibly as a protective response to mucosal injury. ${ }^{12}$ Florey and Harding ${ }^{3}$ created artificial defects in the duodenal mucosa of cats and noted that DGM developed near the ulcer margin, but was absent after complete healing. Rhodes injected cats with histamine, thus causing peptic ulceration and increased prevalence of DGM. Rats injected with pentagastrin and carbachol develop DGM bordering duodenal ulcers. Administration of tetragastrin to rats in the presence of intraduodenal instillation of sodium hydroxide resulted in the development of DGM in $59 \%$, compared with only $23 \%$ in controls who received sodium hydroxide only. ${ }^{6}$

The studies in humans are less clear cut. James was the first to describe DGM in patients with duodenal ulcer (DU). ${ }^{7}$ Subsequent work has shown that the prevalence of DGM varies between $60-100 \%$ in patients with $\mathrm{DU}^{8-12}$ and affects $4 \%$ to $64 \%$ of normal subjects. ${ }^{9}{ }^{13-19}$ DGM is more common in the presence of high acid output, ${ }^{101620}$ is more extensive at low intragastric $\mathrm{pH},{ }^{21}$ and less extensive in those with low acid secretion. ${ }^{11} 22$ These studies did not show a quantitatively significant relation between the extent of DGM and acid output.

In addition to gastric acid, Helicobacter pylori may directly affect DGM. $H$ pylori is able to colonise only gastric type epithelium with its overlying layer of mucus, either gastric mucosa in the stomach, or gastric metaplastic mucosa in the duodenum, ${ }^{8}$ where it may lead to an inflammatory response in the duodenal mucosa (duodenitis). ${ }^{21}$ Paradoxically, the mucosal injury caused by $H$ pylori may result in increased prevalence and extent of DGM as a protective response, and thereby permit more extensive colonisation of the duodenal bulb by $H$ pylori, which may lead to more injury. The inflamed duodenal mucosa may be more susceptible to damage by gastric acid, eventually resulting in ulceration in some subjects. ${ }^{9}$ Furthermore, $H$ pylori may increase the prevalence and extent of DGM by further increasing the amount of acid arriving in the duodenal bulb - this would be especially raised in those who have an $H$ pylori +ve DU..$^{23}$ The relative contribution that gastric acid or $H$ pylori, or both, make to the prevalence and extent of DGM is unclear, but it is important for understanding the aetiology of DU disease.

DGM is randomly distributed in the duodenal bulb and is commonest at the margin of ulcers. Thus Wyatt ${ }^{9}$ took biopsy specimens from all quadrants of the duodenal bulb to estimate the distribution of DGM and found that taking only one anterior biopsy specimen underestimated DGM by $37 \%$. Previous studies $^{10111621}$ of the relation between DGM and acid output have relied on only one or two duodenal bulb biopsy samples to estimate its prevalence, and only semi-quantitative methods were used to estimate the extent of DGM.

A number of different measurements are used to measure gastric acid output. In this study basal acid output (BAO), which is the amount of acid secreted under resting, 
unstimulated conditions, ${ }^{24}$ and two different measurements of parietal cell function were used. Firstly, peak acid output (PAO) in response to a submaximal dose of gastrin releasing peptide $\left(\mathrm{PAO}_{\mathrm{GRP}}\right)$ was determined, which is a measure of the combined functional response of the gastric antrum and body to endogenous gastrin release. ${ }^{23}{ }^{25} \mathrm{El}-\mathrm{Omar}^{23}$ has shown that GRP mediated acid output is six times higher in $H$ pylori positive (+ve) patients with DU than in $H$ pylori negative (-ve) controls; this exaggerated response returns to normal one year after eradication of $H$ pylori. Secondly, and by way of contrast, PAO measured after a maximally effective dose of pentagastrin $\left(\mathrm{PAO}_{\mathrm{Pg}}\right)$, which is an indirect estimate of the total population of functional parietal cells was determined. ${ }^{26}$

The aim of this study was to determine the relation between $\mathrm{BAO}, \mathrm{PAO}_{\mathrm{GRP}}$, and $\mathrm{PAO}_{\mathrm{Pg}}$ and the prevalence and extent of DGM, in the presence or absence of $H$ pylori, in healthy controls and in patients with DU. Multiple duodenal biopsies and a quantitative computerised method for the measurement of the extent of DGM were used.

\section{Methods}

\section{Subjects}

Nineteen patients with DU were studied (Table I). DU was endoscopically diagnosed in all, and was defined as a break in the mucosa of the duodenal bulb more than $5 \mathrm{~mm}$ in diameter, with apparent depth and slough at the base. Ten $H$ pylori +ve patients with DU were studied before, and eight of them were restudied six months after, eradication of $H$ pylori. There were nine $H$ pylori -ve patients with DU. Two of patients with DU had never been infected with $H$ pylori, taken non-steroidal anti-inflammatory drugs (NSAIDs), suffered from Zollinger-Ellison syndrome, Crohn's disease, ectopic pancreatic tissue, sarcoidosis or hypercalcaemia, and will be referred to as idiopathic DU. The remaining seven $H$ pylori -ve patients had symptomatic and endoscopic recurrence of DU at least six months (mean 18 months) after eradication of $H$ pylori, and will be referred to as $H$ pylori -ve recurrent DU. Sixteen healthy controls (six $H$ pylori +ve) without symptoms referable to the upper gastrointestinal tract and with normal endoscopy were studied. None of the subjects had taken NSAIDs within one month, or antisecretory medication within two weeks, ${ }^{27}$ of the study. Table I shows the clinical and demographic details of the subjects.
Determination of $\mathrm{H}$ pylori status

$H$ pylori status was determined by histology (antrum, body, and duodenal bulb biopsy specimens routinely processed and stained with haematoxylin and eosin and Gimenez stains), culture (antrum and duodenal bulb biopsy specimens isolated on selective and nonselective media and microaerobic conditions for up to 10 days), and by the ${ }^{13} \mathrm{C}$-urea breath test (European Standard Protocol, where a result is positive if excess $\delta^{13} \mathrm{CO}_{2}$ excretion exceeds 5 per $\left.\mathrm{mil}^{28}\right)$. Subjects were defined as $H$ pylori positive if they had a positive breath test, positive histology or culture, or all three. Absence of $H$ pylori was defined as failure to detect $H$ pylori in all three tests.

\section{Gastric metaplasia in the duodenal bulb}

Endoscopic four quadrant duodenal bulb biopsy specimens were taken by one endoscopist (AWH) more than $1 \mathrm{~cm}$ away from the edge of DU and more than $1 \mathrm{~cm}$ beyond the pylorus. Biopsy samples were processed routinely, embedded on edge, cut at three levels, and stained with periodic acid Schiff (PAS) to identify DGM. All specimens could be assessed for gastric metaplasia without the need for re-orientation after assessment by light microscopy. DGM was defined as the occurrence of foci of gastric epithelial cells containing apical PAS positive mucin together with the absence of a brush border (Fig 1). The presence and extent of DGM was measured by one observer (AWH), who was unaware of the identity of the samples, in one section from each biopsy specimen using a computer enhanced image intensifier (Seescan Imaging, Cambridge, England) with a hand held tracker ball (mouse). The mouse was calibrated in microns, and the length of the epithelial surface and DGM overlying each complete villus in

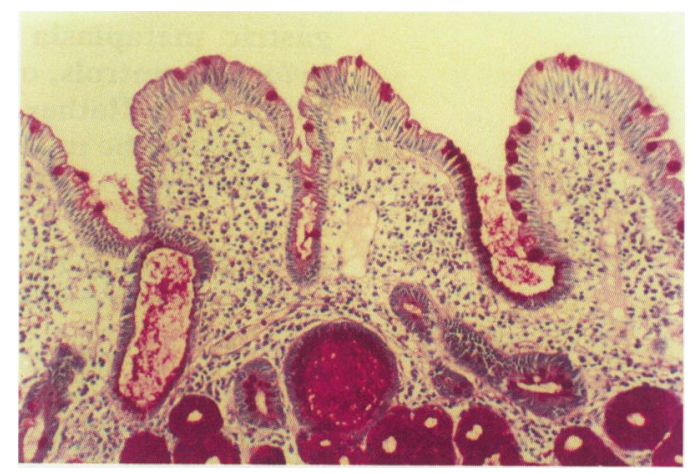

Figure 1: Duodenal bulb biopsy specimen showing foci of gastric metaplasia (stained pink). PAS, original magnification $\times 100$.

TABLE I Subjects studied

\begin{tabular}{llllll}
\hline & Controls & \multicolumn{5}{c}{ DU } \\
\hline Endoscopy & Normal & Normal & DU & DU & Normal \\
H pylori status & negative & positive & negative & positive & $\begin{array}{l}\text { negative (after } \\
\text { pylori eradication) }\end{array}$ \\
Number & & 6 & 9 & 10 & 8 \\
Men & 10 & 5 & 7 & 7 & 6 \\
Age mean (range) & $43(24-40)$ & $34(22-54)$ & $42(26-55)$ & $37(22-58)$ & $40(28-58)$ \\
Current smokers & 3 & 2 & 1 & 3 & 1 \\
\hline
\end{tabular}


each of the four duodenal bulb biopsy specimens were measured. The extent of DGM in each biopsy specimen was calculated as a percentage of the total epithelial surface measured in each biopsy specimen. The median extent of DGM in the four duodenal specimens was calculated for each subject.

\section{Gastric acid output}

Gastric secretion was measured using a standard method. ${ }^{24}$ Within seven days of the endoscopy and after an overnight fast, a nasogastric tube (Salem sump tube, 90-120 cm long, 10-14 French, Sherwood Medical, West Sussex, England) was positioned in the most dependent part of the stomach using the water recovery test. The stomach was aspirated continuously using a suction pump (KV-4, Keymed Limited, Essex, England) at 30-50 $\mathrm{mm} \mathrm{Hg}$. Gastrin releasing peptide (GRP) was purchased (Cambridge Research Biochemicals, Cheshire, England) in $0.5 \mathrm{mg}$ aliquots of freeze dried lyophilised powder. Subsequent preparation was undertaken by the Central Middlesex Hospital Pharmacy under sterile conditions. Each aliquot was made up into a 1 litre stock solution by dissolving in $0.9 \%$ sodium chloride, and $25 \mathrm{ml} \mathrm{5 \%}$ albumin was added to stabilise the solution.

The stomach was emptied and one 30 minute basal aspirate was collected (BAO). Immediately after BAO, GRP was infused into a dorsal vein of the hand using a syringe driver (Flo-Gard DSP, Baxter Healthcare, Berkshire, England) at $40 \mathrm{pmol} / \mathrm{kg} / \mathrm{h}$ for 45 minutes; three consecutive 15 minute stomach aspirates were collected. ${ }^{25}$ On stopping the GRP infusion, there was a 30 minute unstimulated period to allow plasma GRP and acid output to return to normal ${ }^{29-31}$ while gastric secretion was continuously aspirated. Immediately after the unstimulated period, pentagastrin $6 \mu \mathrm{g} / \mathrm{kg}$ (Peptavlon, ICI Pharmaceuticals, Cheshire, England) was injected intramuscularly and three consecutive 15 minute aspirates collected. ${ }^{24}$

All aspirates were stored at $+4^{\circ} \mathrm{C}$ until analysed. Titratable acidity $(\mathrm{mmol} / \mathrm{l})$ was measured with a Metrohm auto-titrator (VA Howe and Co Ltd, Banbury, England), by titration to $\mathrm{pH} 7.0$ with $0.01 \mathrm{M}$ sodium hydroxide. Acid output ( $\mathrm{mmol} / \mathrm{h}$ ) was calculated as the product of volume (l) and titratable acidity $(\mathrm{mmol} / \mathrm{l}){ }^{24}$ The two consecutive highest 15 minute samples were used to establish a 30 minute peak acid output, which was then doubled and expressed in $\mathrm{mmol} / \mathrm{h}^{24}$

Overall the subjects tolerated the gastric secretion studies well. Four subjects (two in each group) experienced transient nausea after the pentagastrin injection, but recovered fully. No adverse effects were reported during GRP infusion.

\section{Statistical methods}

Normally distributed data are expressed as means (SD). Student's unpaired $t$ test was used to compare the significance of the difference between the group means. Acid outputs and extent of DGM are non-Gaussian and data are expressed as medians and ranges. Wilcoxon signed rank test for paired data and MannWhitney $U$ test for unpaired data, were used to compare the significance of the difference between the group medians, where $p<0.05$ was considered to be statistically significant. The relation between gastric acid output and the extent of DGM was analysed using Spearman's rank correlation $\left(r_{\mathrm{s}}\right)$. The significance of the association was tested by comparing $r_{\mathrm{s}}$ with critical values, ${ }^{32}$ where $p<0.05$ was considered to be statistically significant.

\section{Ethics}

The protocol received approval from the Parkside ethical committee and all subjects gave written informed consent.

\section{Results}

\section{Prevalence of gastric metaplasia}

DGM was significantly $(p=0.05)$ more common in patients with DU (17 of $19,89 \%$ ) than in healthy controls (nine of $16,56 \%$ ) (Table II). Prevalence of DGM was not affected by $H$ pylori status. Thus, DGM was found in five of $10 \mathrm{H}$ pylori -ve and in four of six $H$ pylori +ve controls ( $\mathrm{p}>0.05)$, and in nine of $10 \mathrm{H}$ pylori +ve patients with DU and in eight of nine $H$ pylori -ve patients with recurrent or idiopathic DU $(p>0.05)$. The prevalence of DGM in $H$ pylori +ve patients with DU was unchanged six months after eradication of $H$ pylori. Thus it was found in nine of 10 before, and in seven of eight after successful treatment of $H$ pylori $(\mathrm{p}>0.05)$ (Table II).

\section{Extent of gastric metaplasia}

The extent (\%) of DGM was significantly $(p<0.05)$ greater in patients with DU than in healthy controls (Table III). Thus, median (range) extent (\%) of DGM was $28(0-55)$ in patients with DU and $0(0-23)$ in controls (Fig 2). There was no significant $(p>0.05)$

TABLE II Prevalence of gastric metaplasia in the duodenal bulb in $\mathrm{H}$ pylori $+v e$ and -ve controls and in $\mathrm{H}$ pylori -ve patients with recurrent or idiopathic DU and in $\mathrm{H}$ pylori $+v e$ patients with $D U$ before and after eradication of $\mathrm{H}$ pylori

\begin{tabular}{|c|c|c|c|c|c|}
\hline & Controls & & $D U$ & & \\
\hline Prevalence (\%) of DGM & $9 / 16(56 \%)$ & & $17 / 19^{\star}(89 \%)$ & & \\
\hline$H$ pylori status & negative & positive & negative & $\begin{array}{l}\text { positive } \\
\text { (before) }\end{array}$ & $\begin{array}{l}\text { negative (after } \\
H \text { pylori eradication) }\end{array}$ \\
\hline Prevalence (\%) of DGM & $5 / 10(50)$ & $4 / 6(66)$ & $8 / 9^{\star}(89)$ & $9 / 10^{\star}(90)$ & $7 / 8(87 \%)^{\star}$ \\
\hline
\end{tabular}

${ }^{\star}$ denotes statistically significant $(p<0.05)$ difference between controls and patients with DU. 
TABLE III Extent of gastric metaplasia in the duodenal bulb in $\mathrm{H}$ pylori +ve and-ve controls and in $\mathrm{H}$ pylori -ve patients with recurrent or idiopathic DU and in $\mathrm{H}$ pylori +ve patients with $D U$ before and after eradication of $\mathrm{H}$ pylori

\begin{tabular}{llllll}
\hline & Controls & & $D U$ & \\
\hline H pylori status & negative & positive & negative & positive & $\begin{array}{l}\text { negative (after } \\
\text { (before) }\end{array}$ \\
$\begin{array}{l}\text { Median (range) extent } \\
(\%) \text { of DGM }\end{array}$ & $0(0-23)$ & $0(0-25)$ & $26^{\star}(0-100)$ & $28^{\star}(0-55)$ & $17^{\star}(0-77)$ \\
\hline
\end{tabular}

*denotes statistically significant $(p<0.05)$ difference between controls and patients with DU.

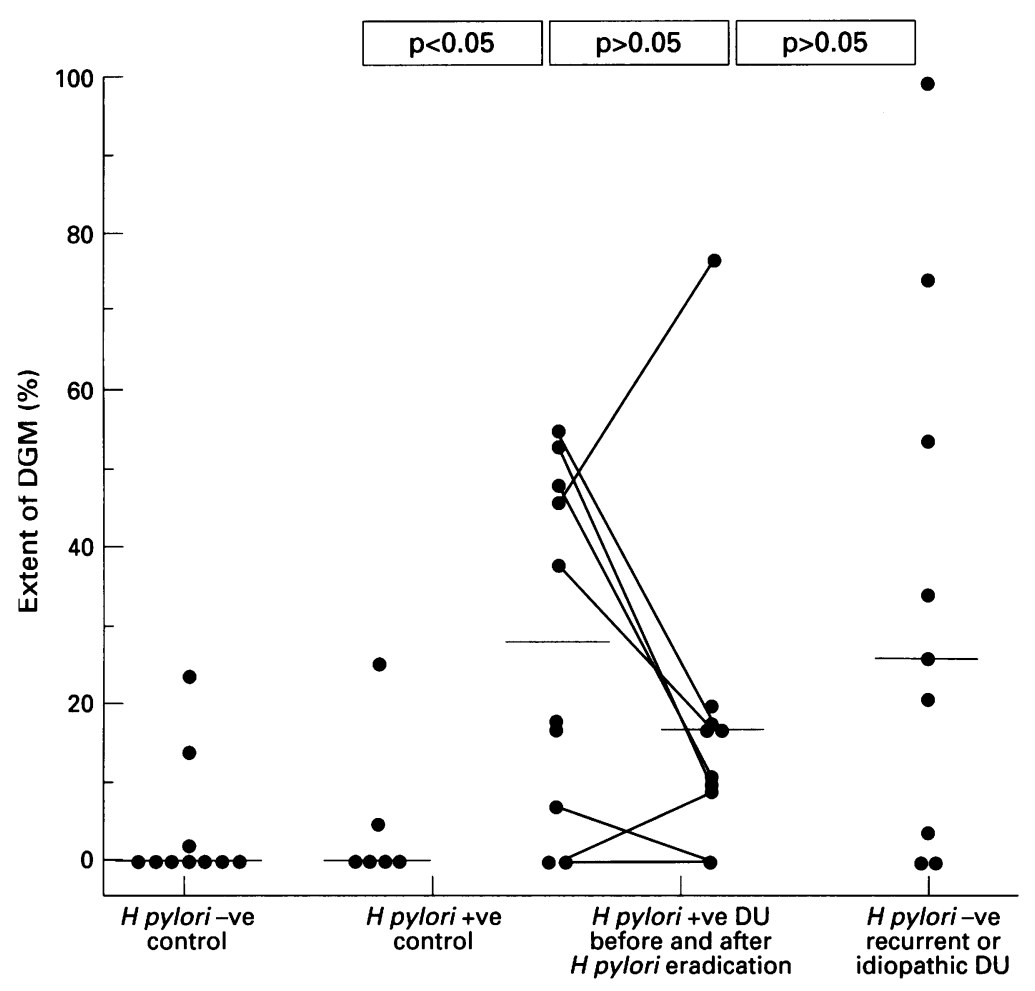

Figure 2: Extent of gastric metaplasia in the duodenal bulb (DGM) in $\mathrm{H}$ pylori -ve and $+v e$ controls and in $\mathrm{H}$ pylori +ve patients with $\mathrm{DU}$ before and six months after eradication of $\mathrm{H}$ pylori, and in $\mathrm{H}$ pylori -ve patients with recurrent or idiopathic DU. Horizontal bars are medians.
The median (range) extent (\%) of DGM in the $H$ pylori +ve patients with DU fell from $28(0-55)$ to $17(0-77)$ six months after eradication of $H$ pylori (Table III, Fig 2). The effect of eradication of $H$ pylori on DGM was highly variable, and statistical analysis did not show a significant difference $(p>0.05)$ between the same group before and after $H$ pylori eradication. DGM in the patients with DU six months after eradication of $H$ pylori was still significantly $(\mathrm{p}=0.03)$ greater in extent than in $H$ pylori-ve and in $H$ pylori +ve controls (Table III, Fig 2).

Gastric acid output

Basal (BAO) and stimulated $\left(\mathrm{PAO}_{\mathrm{GRB}}, \mathrm{PAO}_{\mathrm{Pg}}\right)$ acid outputs $(\mathrm{mmol} / \mathrm{h})$ were significantly $(\mathrm{p}<0.05)$ higher in $H$ pylori +ve patients with DU before treatment than in $H$ pylori -ve and +ve controls (Table IV).

Of the $10 \mathrm{H}$ pylori +ve patients with DU, eight agreed to be restudied six months after $H$ pylori eradication. At endoscopy DU had healed in all these eight patients, with no evidence of macroscopic duodenitis. BAO and PAO $_{\text {GRP }}$ are available for only seven of these eight patients (in one patient gastric secretion collected during $\mathrm{BAO}$ and $\mathrm{PAO}_{\mathrm{GRP}}$ contained no titratable acidity or bile). This may have resulted from a displaced or blocked tube. Six months after $H$ pylori eradication, median (range) $\mathrm{BAO}, \mathrm{PAO}_{\mathrm{GRP}}$, and $\mathrm{PAO}_{\mathrm{Pg}}(\mathrm{mmo} / \mathrm{h})$ were 3 (1-11), $11(0.9-39)$, and 29 (8-52), respectively (Table IV); all significantly $(\mathrm{p}<0.05)$ lower than before $H$ pylori eradication, and not significantly different from the output in the $H$ pylori -ve and +ve controls. The median \% (range) decrease after eradication of $H$ pylori was not significantly different for the three variables of acid output measured: BAO decreased by $50 \%$ (20-94), PAO $_{\text {GRP }}$ by $55 \%(15-60)$, and $\mathrm{PAO}_{\mathrm{Pg}}$ by $33 \%(9-76)$.

$\mathrm{BAO}, \mathrm{PAO}_{\mathrm{GRP}}$, and $\mathrm{PAO}_{\mathrm{Pg}}(\mathrm{mmol} / \mathrm{h})$ were not significantly different $(\mathrm{p}>0.05)$ between $H$ pylori +ve patients with DU before treatment and $H$ pylori -ve patients with recurrent or idiopathic DU (Table IV).

TABLE IV Basal and stimulated peak acid outputs in $\mathrm{H}$ pylori -ve and +ve controls and in $\mathrm{H}$ pylori -ve patients with recurrent or idiopathic DU, and in $\mathrm{H}$ pylori $+v e$ patients with $D U$ before and six months after eradication of $\mathrm{H}$ pylori

\begin{tabular}{lccccc}
\hline $\begin{array}{l}\text { Median (range) acid } \\
\text { output (mmolh) }\end{array}$ & $\begin{array}{l}\mathrm{H} \text { pylori -ve } \\
\text { Controls }\end{array}$ & $\begin{array}{l}\mathrm{H} \text { pylori }+v e \\
\text { Controls }\end{array}$ & $\begin{array}{l}\mathrm{H} \text { pylori-ve } \\
\text { recurrent/idiopathic } \\
D U\end{array}$ & $\begin{array}{l}\mathrm{H} \text { pylori }+v e D U \\
\text { before } \mathrm{H} \text { pylori } \\
\text { eradication }\end{array}$ & $\begin{array}{l}\mathrm{H} \text { pylori }+v e D U \\
\text { after } \mathrm{H} \text { pylori } \\
\text { eradication }\end{array}$ \\
\hline $\mathrm{BAO}$ & $2(0 \cdot 2-6)$ & $1(0-9)$ & $6(0-20)$ & $9(2-19)^{\star}$ & $3(1-11)$ \\
PAO $_{\mathrm{GRP}}$ & $11(1-25)$ & $9(0-26)$ & $20(1-31)$ & $31(0 \cdot 3-55)^{\star}$ & $11(0 \cdot 9-39)$ \\
PAO $_{\mathrm{PB}_{\mathrm{g}}}$ & $22(12-40)$ & $24(1-49)$ & $37(24-69)^{\star}$ & $43(19-69)^{\star}$ & $29(8-52)$ \\
\hline
\end{tabular}

*denotes statistically significant $(p<0.05)$ difference between controls and patients with DU. 


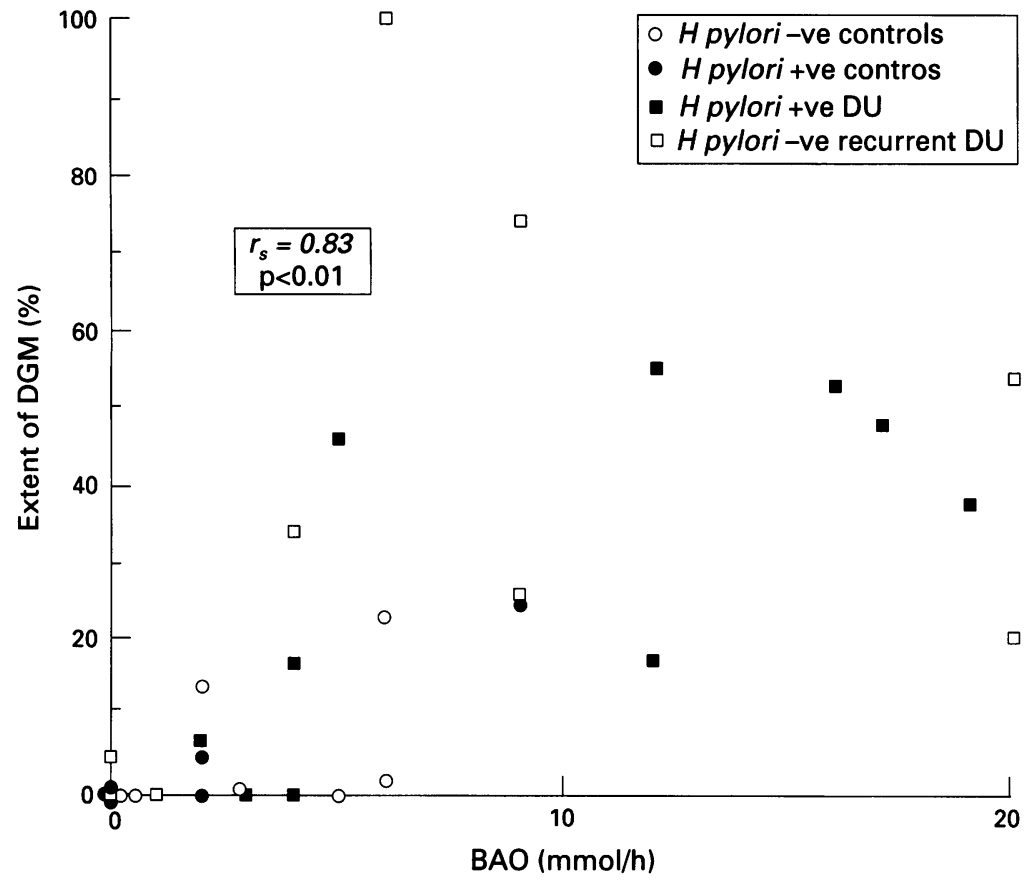

Figure 3: Relation between basal acid output (BAO) and extent of duodenal gastric metaplasia (DGM) in controls and patients with duodenal ulcer.

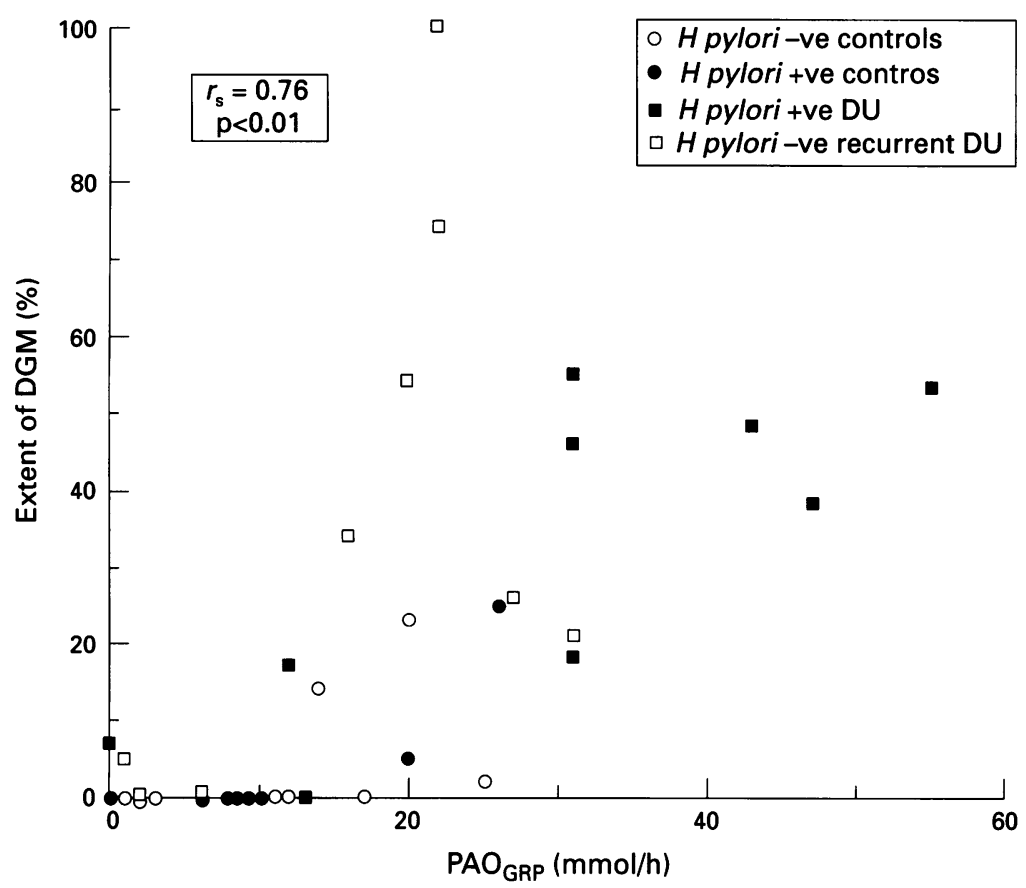

Figure 4: Relation between GRP stimulated acid output $\left(P A O_{\text {GRP }}\right)$ and extent of duodenal gastric metaplasia (DGM) in controls and patients with duodenal ulcer.

\section{Relation between prevalence of DGM and acid output}

The upper limit in healthy subjects for BAO and $\mathrm{PAO}_{\mathrm{Pg}}$ are about $5 \mathrm{mmol} / \mathrm{h}$ and $30 \mathrm{mmol}$ $h$, respectively. ${ }^{24}$ The normal range for acid output after submaximal doses of GRP $\left(\mathrm{PAO}_{\mathrm{GRP}}\right)$ has not been defined. Using these values as a cut off between normality and acid hypersecretion, DGM was found to be more common in the presence of acid hypersecretion, either in the basal, or in the stimulated state. Thus, DGM was significantly $(p<0.001)$ more common in subjects (controls and patients with DU) with $\mathrm{BAO}>5 \mathrm{mmol} / \mathrm{h}$ (14 of 14), than in subjects with BAO $<5 \mathrm{mmol} /$ $\mathrm{h}$ (nine of 21). DGM was significantly $(\mathrm{p}=0.01)$ more common in subjects with $\mathrm{PAO}_{\mathrm{Pg}}>30$ $\mathrm{mmol} / \mathrm{h}$. Thus, DGM was found in 11 of 11 $(100 \%)$ subjects with $\mathrm{PAO}_{\mathrm{Pg}}>40 \mathrm{mmol} / \mathrm{h}$, and in 16 of $18(89 \%)$ subjects with $\mathrm{PAO}_{\mathrm{Pg}}>30$ $\mathrm{mmol} / \mathrm{h}$, but in only eight of $17(47 \%)$ subjects with $\mathrm{PAO}_{\mathrm{Pg}}<30 \mathrm{mmol} / \mathrm{h}(\mathrm{p}=0.01)$.

\section{Relation between the extent of DGM and acid output}

The relation between $\mathrm{BAO}, \mathrm{PAO}_{\mathrm{GRP}}$, and PAO $_{\mathrm{Pg}}$ and extent (\%) of DGM in all subjects is shown in Figures 3-5. In the 35 subjects taken as a whole, there were significant $(\mathrm{p}<0.01)$ direct correlations between BAO, $\mathrm{PAO}_{\mathrm{GRP}}$, and $\mathrm{PAO}_{\mathrm{Pg}}$ and median extent $(\%)$ of DGM, with $r_{s}$ values of $0.83,0.76$, and 0.65 , respectively.

In $H$ pylori +ve patients with DU there were significant $(\mathrm{p}<0.05)$ direct correlations between median extent of DGM and BAO, $\mathrm{PAO}_{\mathrm{GRP}}$ and $\mathrm{PAO} \mathrm{Pg}_{\mathrm{Pg}}$, with $r_{s}$ of $0.73,0.76$, and $0 \cdot 69$, respectively.

In $H$ pylori -ve patients with recurrent or idiopathic DU, the relation between median extent of DGM and BAO was significant $\left(r_{\mathrm{s}}=0.66, \mathrm{p}<0.05\right)$, but not between $\mathrm{PAO}_{\mathrm{GRP}}$ $\left(r_{\mathrm{s}}=0.61, \mathrm{p}>0.05\right)$ or $\mathrm{PAO}_{\mathrm{Pg}}\left(r_{\mathrm{s}}=0.45, \mathrm{p}>0.05\right)$.

There were no significant $(\mathrm{p}>0.05)$ correlations between $\mathrm{BAO}, \mathrm{PAO}_{\mathrm{GRP}}$, and $\mathrm{PAO}_{\mathrm{Pg}}$ and median extent of DGM in $H$ pylori -ve controls, with $r_{\mathrm{s}}$ of $0.40,0.54$, and 0.30 , respectively. The same was true for $H$ pylori tve controls, with $r_{\mathrm{s}}$ values of $0.63,0.52$, and 0.23 for $\mathrm{BAO}, \mathrm{PAO}_{\mathrm{GRP}}$, and $\mathrm{PAO}_{\mathrm{Pg}}$, respectively.

\section{Discussion}

Prevalence of gastric metaplasia

This study has shown that DGM was significantly more common in patients with DU than in healthy subjects, which is in agreement with previous results. ${ }^{12} 2133-36$ The prevalence of DGM was shown to be unaffected by the presence of $H$ pylori, also confirming previous work. ${ }^{9}{ }^{12}{ }^{37}$ Earlier studies ${ }^{9}{ }^{13-19}$ reported DGM in $4 \%$ to $64 \%$ of healthy subjects. In this study, DGM was detected in nine of $16(56 \%)$ healthy controls. Similar data were reported by Kreuning et $a l,{ }^{13}$ who also took four directed duodenal bulb biopsy specimens and found DGM in 32 of $50(64 \%)$ healthy subjects $(H$ pylori status not determined). However, there are five studies that reported that DGM was less common in controls: in these it was found in $4 \%$ to $30 \%$ of healthy adults. ${ }^{14-18}$ How can this wide variation in the reported prevalence be explained? In these latter studies only one or two anterior wall duodenal bulb biopsy specimens were taken to determine the prevalence of DGM; thus the results may be affected by sampling error. Wyatt ${ }^{9}$ calculated that a single anterior wall biopsy specimen detected only $63 \%$ of patients with DGM diagnosed by quadrantic duodenal bulb biopsy specimens. In this study, a single anterior wall biopsy would have detected DGM in only six of $16(37 \%)$ controls, compared with nine of 


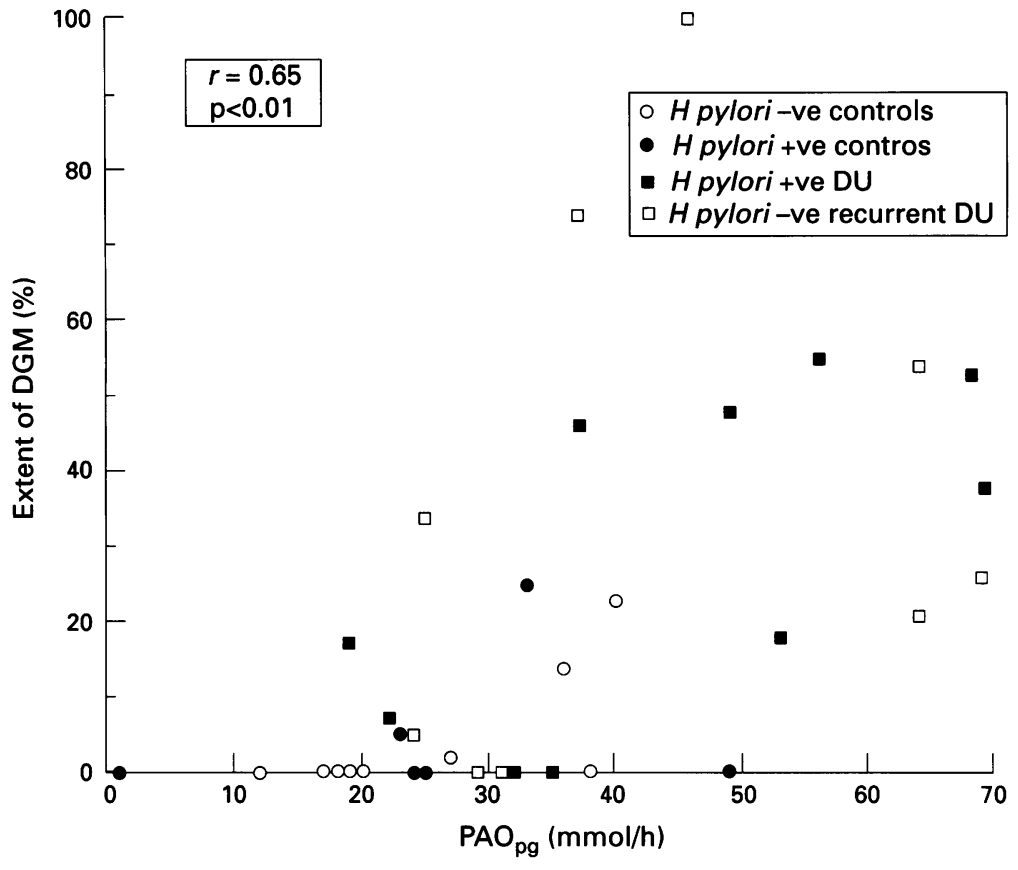

Figure 5: Relation between pentagastrin stimulated peak acid output $\left(P A O_{P g}\right)$ and extent of duodenal gastric metaplasia (DGM) in controls and patients with duodenal ulcer.

$16(56 \%)$ found by four quadrant biopsy specimens. Thus in agreement with Wyatt, one biopsy specimen would have detected only $67 \%$ of DGM found by quadrantic duodenal bulb biopsy specimens. This is not surprising, as DGM is randomly distributed within the duodenal bulb and its prevalence therefore may be underestimated if only one site is sampled. It is possible that the five studies of the prevalence of DGM that used only anterior wall duodenal biopsy specimens to assess DGM may have underestimated the true prevalence of DGM.

\section{Extent of gastric metaplasia}

The extent of DGM was significantly greater in patients with DU than in healthy controls, in agreement with other studies. ${ }^{9122135}$ These previous studies used only semi-quantitative methods to assess the extent of DGM. Thus, the percentage of the duodenal epithelium that was replaced by DGM was assessed by one histopathologist (or sometimes two) using a semi-quantitative grading system ( 0 to 4 ) depending on whether one pathologist estimated that it covered $<5 \%, 5-20 \%, 20-50 \%$ or $>50 \%$ of the surface in the biopsy specimen, respectively. ${ }^{9}$ Using this method, it was not possible to calculate the average extent of DGM for each subject. When there was more than one histopathologist, the same biopsy specimens were reviewed by a second observer and the degree of interobserver variation determined. In the study by Wyatt ${ }^{9}$ there was concurrence between the two pathologists in 79 of 100 of the biopsy specimens, and in five cases there was a difference of more than one grade. This gave a $\kappa$ value of 0.66 (intra-class correlation coefficient; value of $\geq 0.75$ indicates excellent agreement beyond chance expectation $^{38}$ ), indicating a high level of agreement over the five categories. In this study a quantitative method was used. This entailed measuring the actual length of the duodenal epithelium and the length of DGM overlying a complete villus. All measurements were taken by a single observer (AWH), without knowledge of the identification of the specimens. Subsequently, the median extent of DGM for each subject was calculated. Using this new technique, we were able to quantify the difference in median extent of DGM between patients with DU (27\%) and healthy controls $(0 \%)$.

Our data show that there was no significant difference in the extent (\%) of DGM between $H$ pylori-ve and $H$ pylori +ve subjects taken as a whole (controls and DU), with median (range) $2(0-100) v 12(0-55)$, respectively. These findings suggest that infection with $H$ pylori does not affect the extent of DGM, and this is in agreement with Noach et al. ${ }^{12}$ By contrast, Wyatt ${ }^{9}$ found that the extent of DGM was significantly greater in $H$ pylori +ve than in $H$ pylori-ve patients with non-ulcer dyspepsia (NUD); $21 \%$ of $H$ pylori +ve patients with NUD had $>5 \%$ DGM compared with $15 \%$ of $H$ pylori-ve patients with NUD ( $\mathrm{p}=0.002)$.

These discordant results could be because of the patients studied or the methods used, or both. In this study, the $H$ pylori +ve patients with DU have been compared with three different control groups:- $H$ pylori-ve and +ve healthy controls, and $H$ pylor $i$-ve patients with recurrent, or idiopathic DU. Wyatt ${ }^{21}$ studied biopsy specimens from a heterogenous group of patients (254 patients with NUD, 13 patients with previous HSV for DU, and 23 patients with DU). $H$ pylori -ve patients with DU were not studied; all patients with current or previous DU were $H$ pylori +ve. The importance of the $H$ pylori -ve patients with DU as a control group is emphasised by excluding them from the analysis; the median extent (\%) of DGM then becomes significantly $(\mathrm{p}<0.05)$ greater in $H$ pylori + ve subjects $(12$, range $0-55)$ than in $H$ pylori -ve controls ( 0 , range $0-23) . H$ pylori -ve patients with DU are a more important control group than $H$ pylori -ve healthy controls or patients with NUD because they have a DU diathesis, an increased $\mathrm{PAO}_{\mathrm{Pg}}$, but in the absence of infection with $H$ pylori. Studies on $H$ pylori -ve patients with recurrent or idiopathic DU allows the effect of gastric acid hypersecretion on the extent of DGM to be assessed independently of $H$ pylori infection.

Wyatt $e t a l^{9}$ used a single anterior duodenal wall biopsy to estimate the extent of DGM. In this study, use of the anterior wall biopsy specimen instead of the four quadrant duodenal bulb biopsy specimens to estimate the extent of DGM in the $H$ pylori +ve patients with DU would result in a significant overestimate. Thus, the median extent (\%) of DGM in $H$ pylori +ve patients with DU was 68 (range 0-100) using a single anterior wall duodenal biopsy specimen compared with 28 (range $0-55$ ) with quadrantic biopsy specimens $(\mathrm{p}<0.05)$. The median extent of DGM in $H$ pylori-ve and +ve controls was not 
changed significantly when assessed by single or quadrantic biopsy specimens of the duodenal bulb. The difference in the extent of DGM between $H$ pylori +ve and -ve patients found by Wyatt ${ }^{9}$ may result therefore from a combination of sampling error leading to an overestimate of the extent of DGM in the $H$ pylori +ve patients with DU and a lack of a suitable control group for the $H$ pylori tve patients with DU.

\section{Prevalence of gastric metaplasia in the duodenal} bulb and acid output

Animal $^{3-6}$ and human ${ }^{101621}$ studies have shown that DGM is more common in the presence of acid hypersecretion. In particular, DGM was significantly more common in patients with DU with very high acid secretion $\left(\mathrm{PAO}_{\mathrm{Pg}}>30 \mathrm{mmol} / \mathrm{h}\right) .{ }^{10}{ }^{16}$ Our results have confirmed that DGM was significantly $(p<0.05)$ more common in patients with DU and $\mathrm{PAO}_{\mathrm{Pg}}>30 \mathrm{mmol} / \mathrm{h}(12$ of 12$)$ than in patients with DU and $\mathrm{PAO}_{\mathrm{Pg}}<30 \mathrm{mmol} / \mathrm{h}$ (four of seven). Moreover, and in agreement with Biad et $a l,{ }^{16} \mathrm{DGM}$ was significantly more common in patients with DU in the presence of basal acid hypersecretion $(\mathrm{BAO}>5 \mathrm{mmol} / \mathrm{h}$ ) or high peak acid output $\left(\mathrm{PAO}_{\mathrm{Pg}}\right)$, or both; both of which are dependent on the functional parietal cell mass. ${ }^{24} 39$ These findings underline the importance of duodenal bulb acidity in the aetiology of DGM.

\section{Extent of gastric metaplasia in the duodenal bulb and acid output}

Our data show a highly significant $(p<0.01)$ direct relation between the extent of DGM and gastric acid output (Figs 3-5): a newly established relation. Thus the extent of DGM was highest in those subjects with the greatest basal or stimulated peak acid outputs, or both. Earlier work by Wyatt ${ }^{9}{ }^{21}$ reported that the extent of DGM was greater in subjects with a low fasting gastric juice $\mathrm{pH}$, but there are no reports, as far as we are aware, that quantify the relation between the extent of DGM and acid output.

\section{Effect of $\mathrm{H}$ pylori eradication on gastric metaplasia}

These results have shown that neither the prevalence, nor the extent of DGM in $H$ pylori +ve patients with DU changed significantly six months after eradication of $H$ pylori, and this is in keeping with the findings of others ${ }^{12} 34$ (Table II and Table III, Fig 2). In this study the median extent of DGM was almost halved from $28 \%$ to $17 \%$ six months after eradication of $H$ pylori, but the difference did not achieve statistical difference. By contrast, Khulusi et $a l^{40}$ reported that the prevalence of DGM was unchanged, but that the median extent of DGM significantly decreased from 16 to $8 \%$, at a median of 10 months after eradication of $H$ pylori, and this difference achieved statistical significance. It is possible that sampling errors may account for these discordant results. To estimate the extent of DGM Khulusi et al examined three duodenal biopsy specimens, one from the ulcer margin and two from the anterior wall of the duodenal bulb away from the ulcer. DGM is greatest in extent at the ulcer margin, ${ }^{10} 41^{42}$ and decreases after ulcer healing. ${ }^{41}$ It follows that sampling the ulcer margin may lead to an underestimate of the extent of DGM in the duodenal bulb after the ulcer has healed. Furthermore, anterior wall duodenal bulb biopsy specimens may not be representative of the extent of DGM in the remainder of the duodenal bulb. ${ }^{9}$ It is possible therefore that sampling errors may have contributed to the significantly decreased extent of DGM previously reported.

Significant decrease in the prevalence or extent of DGM after eradication of $H$ pylori and normalisation of acid output in patients with DU was not shown by our data. Several issues need to be considered. Firstly, it is possible that the follow up interval was too short to detect a significant decrease in the prevalence or extent of DGM, or both after eradication of $H$ pylori. This is perhaps unlikely, because Noach et $a l^{12}$ who restudied their patients one year after eradication of $H$ pylori still failed to detect a significant reduction in DGM.

Secondly, a fall in acid output (33-55\%) after eradication of $H$ pylori may not have been sufficient to affect DGM. A number of groups did not find decreased prevalence or extent of DGM after treatment with $\mathrm{H}_{2}$ receptor antagonists, ${ }^{34}{ }^{43-46}$ which inhibit acid secretion to a similar degree (45 to $65 \%) .{ }^{47}{ }^{48}$ Profound longterm hypochlorhydria induced by either omeprazole $^{1249}$ or by vagal denervation ${ }^{2150}$ was necessary to significantly decrease the prevalence, or extent of DGM. Omeprazole 20 mg daily decreases 24 hour intragastric acidity by about $90 \%,{ }^{48}$ a similar figure to vagal denervation. ${ }^{24}$ In view of these data, it is not surprising that a significant decrease in the prevalence or extent of DGM in patients with DU was not recorded in this study after eradication of $H$ pylori, as the resultant decrease in acid secretion was more akin to that after treatment with $\mathrm{H}_{2}$ receptor antagonists, than after vagal denervation or omeprazole therapy.

Thirdly, there may have been a significant decrease in the prevalence and extent of DGM after eradication of $H$ pylori, and this study may have failed to detect it (Type II error ${ }^{32}$ ). The extent of DGM was highly variable within a subject, for example, in one $H$ pylori tve patient with DU the extent of DGM in the four duodenal bulb biopsy specimens varied between $0 \%$ and $100 \%$ before, and $0 \%$ and $100 \%$ after, eradication of $H$ pylori. This problem can be decreased by the use of multiple directed biopsies, but even this manoeuvre does not overcome the difficulty completely. Moreover, a small number of patients with DU were studied before and after eradication of $H$ pylori, and this may have possibly contributed towards a Type II error.

In conclusion, we have shown that DGM is significantly more common in subjects with 
high basal and stimulated peak acid outputs, and that there was a significant direct relation between the extent of DGM and gastric acid output. The prevalence and extent of DGM were similar regardless of presence, or absence of $H$ pylori in healthy controls and patients with DU. Moreover, neither the prevalence nor extent of DGM were changed significantly six months after eradication of $H$ pylori in patients with DU; data which does not support a primary role of $H$ pylori in the pathogenesis of DGM. Our results provide further evidence to support the primary aetiological role of gastric acid secretion in the development of DGM.

We wish to thank Dr M Jacyna (Northwick Park Hospital, Harrow) for allowing us to study two of his patients. We thank the nursing staff of the endoscopy units of Central Middlesex the nursing staff of the endoscopy units of Central Middlesex and St Mary's Hospitals, and Mr Kang Li, Department of Surgery, Royal Postgraduate Medical School for their expert help. We are

cooperation.

Part of this work was presented at the Spring Meeting of the British Society of Gastroenterology in April 1995

AWH was supported by a grant from Lederle Laboratories, Gosport, UK.

1 Liu KC, Wright NA. The migration pathway of epithelial cells on human duodenal villi: the origin and fate of gastric metaplasia cells in duodenal mucosa. Epith Cell Biol 1992 1: 53-8.

2 Khulusi S, Hanby AM, Marrero JM, Patel P, Mendall MA Badve S, et al. Expression of trefoil peptides pS2 and human spasmolytic polypeptide in gastric metaplasia at the margin of duodenal ulcers. Gut 1995; 37: 205-9.

3 Florey HW, Harding HE. The healing of artificial defects of the duodenal mucosa. $\mathcal{f}$ Pathol $1935 ; 40: 211-8$.

4 Rhodes J. Experimental production of gastric epithelium in the duodenum. Gut 1964; 5: 454-8.

5 Gaskin RJ, Gad A, Barros D'Sa AAJ, Joffe SN, Baron JH Natural history and morphology of secretagogue-induced duodenal ulcers. Gastroenterology 1975; 69: 903-10.

6 Tatsuta M, Iishi H, Yamamura H, Yamamoto R, Taniguch $\mathrm{H}$. Enhancement by tetragastrin of experimental in duction of gastric epithelium in the duodenum. Gut 1989 30: $311-5$.

7 James AH. Gastric epithelium in the duodenum. Gut 1964 5: $285-94$

8 Steer HW. Surface morphology of the gastroduodena mucosa in duodenal ulceration. Gut $1984 ; 25$ : 1203-10.

9 Wyatt J, Rathbone BJ, Sobala GM, Shallcross T, Heatley RV, Axon ATR, et al. Gastric epithelium in the duodenum: Its association with Helicobacter pylori and inflammation. $₹$ Clin Pathol 1990; 43: 981-6.

10 Patrick WJA, Denham D, Forrest APM. Mucous change in the human duodenum: a light and electron microscopic study and correlation with disease and gastric acid study and correlation with disea

11 Amarapurkar DN, Parikh SS, Prabhu SR, Kalro RH Desai HG. Is gastric metaplasia essential for duodena ulcer? $\mathcal{F}$ Clin Gastroenterol 1993; 17: 204-6.

12 Noach LA, Rolf TM, Bosma NB, Schwartz MP, Oosting J, Rauws EAJ, Tytgat GNJ. Gastric metaplasia and Helicobacter pylori infection. Gut 1993; 34: 1510-4.

13 Kreuning J, Bosman FT, Kuiper G, Wal AMvd, Lindeman $\mathrm{J}$. Gastric and duodenal mucosa in 'healthy' individuals. $\mathcal{F}$ Clin Pathol 1978; 31: 69-77.

14 Greenlaw R, Sheahan DG, Deluca V, Miller D, Myerson D, Myerson P. Gastroduodenitis. A broader concept of peptic ulcer disease. Dig Dis Sci 1980; 25: 660-72.

15 Geptic ulcer disease. Dig Dis Sci 1980; 25: 660-72. Scand 7 Gastroenterol $1989 ; 24: 10-2$.

16 Biad A, Hamladji RM, Bouhadef A. Gastric metaplasia in normal man and patient with duodenal ulcer disease. Gut 1994; 35 (suppl 4): A131.

17 Cotton PB, Price AB, Tighe JR, Beales JSM. Preliminary evaluation of 'duodenitis' by endoscopy and biopsy. $B M \mathcal{J}$ 1973; 3: 430-3.

18 Min Y, Lee BW, Chi HS, Lee JK. The incidence of gastric metaplasia in patients with duodenal ulcer.(Abstract). Di Dis Sci 1986; 31: 299S.

19 Shabib S, Cutz E, Drumm B, Sherman P. Helicobacter pylor infection is associated with gastric metaplasia in the duodenum. Gastroenterology 1992; 102: A163.

20 Parrish JA, Rawlins DC. Intestinal mucosa in the ZollingerEllison syndrome. Gut 1965; 6: 286-9.

21 Wyatt JI, Rathbone BJ, Dixon MF, Heatley RV. Campylobacter pyloridis and acid induced gastric 1987; 40: 841-8.

22 Recavarren-Arce S, Leon-Barua R, Cok J, Rodriguez C, Berendson R, Gilman RH, et al. Low prevalence of gastric metaplasia in the duodenal mucosa in Peru. $\mathscr{f}$ Clin Gastroenterol 1992; 15: 296-301.

23 El-Omar E, Penman I, Dorrian CA, Ardill JES, McColl KEL. Eradicating Helicobacter pylori infection lowers gastrin mediated acid-secretion by two thirds in patients with duodenal ulcer. Gut 1993; 34: 1060-5.

24 Baron JH. Clinical tests of gastric secretion. London: Macmillan Press, 1978.

25 El-Omar EM, Penman ID, Spence E, Ardill JES McColl KEL. The GRP test: a new clinical test of acid secretion - reproducibility data. Eur $\mathcal{F}$ Gastroenterolo Hepatol 1994; 6: 417-21.

26 Card WI, Marks LN. The relationship between acid output of the stomach following 'maximal' histamine stimulation and the parietal cell mass. Clin Sci 1960; 19: 147-52. 27 Langman MJS. Aetiology of peptic ulcer. In: Misiewicz JJ,
Pounder RE, Venables CW, eds. Diseases of the gut and pancreas. Oxford: Blackwell Scientific, 1994; 246-58.

28 Logan RPH, Polson RJ, Misiewicz JJ, Rao G, Karim NQ, Newell D, et al. Simplified single sample ${ }^{13}$ Carbon urea breath test for Helicobacter pylori: comparison with histology, culture and ELISA serology. Gut 1991; 32: 1461-4.

29 Wood SM, Jung RT, Webster JD, Ghatei MA, Adrian TE Yanaihara, et al. The effect of the mammalian neuropeptide, gastrin releasing peptide (GRP), on gastrointestinal and pancreatic hormone secretion in man. Clin Sci 1983; 65: 365-71.

30 Ghatel MA, Jung RT, Stevenson JC, Hillyard CJ, Adrian TE, Lee YC, et al. Bombesin: action on gut hormones and calcium in man. 7 Clin Endocrinol Metab 1982; 54: 980-5.

31 Helman CA, Hirschowitz BI. Divergent effects of bombesin and bethanechol on stimulated gastric secretion in duodenal ulcer and in normal men. Gastroenterology 1987; 92: 1926-33.

32 Kirkwood BR. Essentials of medical statistics. Oxford: Blackwell Scientific, 1988.

33 Carrick J, Lee A, Hazell S, Ralston M, Daskalopoulos G. Campylobacter pylori, duodenal ulcer and gastric metaplasia: possible role of functional heterotopic tissue in plasia: possible role of functional

34 Shabib S, Cutz E, Drumm B, Sherman P. Gastric metaplasia, duodenal ulcer and duodenitis in association with Helicobacter pylori infection in children. Ir $\mathcal{F} M e d S c i$ 1992; 161 (suppl 10): 11-2

35 Andersen LP, Holck S, Elsborg L, Justesen T. The Helicobacter pylori colonised duodenal mucosa and gastric metaplasia. APMIS 1991; 99: 244-8.

36 Coelho LGV, Das SS, Payne A, Karim QN, Baron JH, Walker MM. Campylobacter pylori in oesophagus, antrum and duodenum. Dig Dis Sci 1989; 34: 445-8.

37 Burette A, De Prez C, Glupczynski Y, Nyst JF, Deltenre M Prevalence of gastric metaplasia and Campylobacter pylor Prevalence of gastric metaplasia and Campylobacter pylor In: Megraud F, Lamouliatte H, eds. Gastroduodenal In: Megraud F, Lamouliatte $\mathrm{H}$, eds. Gastroduodenal Science, $1989 ; 327-31$

38 Landis JR, Koch GG. Biometrics 1977; 33: 159-74.

39 Roxburgh JC, Whitfield P, Hobsley M. Parietal cell sensitivity in humans: controls and duodenal ulce subjects, smokers and non-smokers. Eur $\mathcal{F}$ Gastroenterol Hepatol 1994; 6: 235-40.

40 Khulusi S, Mendall MA, Badve S, Patel P, Finlayson C, Northfield TC. Effect of Helicobacter pylori eradication on gastric metaplasia of the duodenum. Gut 1995; 36: 193-7.

41 Malfertheiner P, Bode G, Stanescu A, Ditschuneit H. Gastric metaplasia and Campylobacter pylori in duodenal ulcer disease: an ultrastruct

42 Caselli M, Trevisani L, Aleotti A, Bovolenta MR Stabellini G. Gastric metaplasia in duodenal bulb and Campylobacter-like organisms in development of duodenal ulcer. Dig Dis Sci 1989; 34: 1374-8.

43 Tovey FI, Husband EM, Yiu YC, Baker L, McPhail G, Lewin MR, et al. Comparison of relapse rates and of mucosal abnormalities after healing of duodenal ulceration and after one year's maintenance with cimetidine or sucralfate: a light and electron microscope study. Gut 1989; 30: 586-93.

44 Jonsson KA, Strom M, Bodemar G, Norrby K. Histologic changes in the gastroduodenal mucosa after long-term medical treatment with cimetidine or parietal cell vagotomy in patients with juxtapyloric ulcer disease. vagotomy in patients with juxtapyloric

45 Moshal MG, Gregory MA, Pillay C, Spitaels JM. Does the duodenal cell ever return to normal? A comparison between treatment with cimetidine and DeNol. Scand $\mathcal{f}$ Gastroenterol 1978; 13: 48-51.

46 Madsen JE, Vetvik K, Aase S. Helicobacter associated duodenitis and gastric metaplasia in duodenal ulcer patients. APMIS 1991; 99: 997-1000.

47 Merkl HS, Witzel L, Walt RP, Neumann J, Scheurle E, Kaufmann D, et al. Comparison of ranitidine $300 \mathrm{mg}$ twice daily, $300 \mathrm{mg}$ at night and placebo on 24-hour intragastric acidity of duodenal ulcer patients. Aliment Pharmacol Therap 1987; 1: 217-23.

48 Jones DB, Howden CW, Burget DW, Kerr GD, Hunt RH. Acid suppression in duodenal ulcer: a meta-analysis to Acid suppression in duodenal ulcer: a meta-analysis to
define dosing with antisecretory drugs. Gut 1987; 28: define dosi.

49 Khulusi S, Patel P, Badve S, Lloyd R, Marrero JM, Finlayson C, et al. Pathogenesis of gastric metaplasia in
duodenal ulcer disease. Gut 1995; 36 (suppl 1): A51.

50 Friess H, Malfertheiner P, Flock F, Baczako K, Stanescu A Buchler M. Elimination of Helicobacter pylori by single shot antibiotic treatment in patients undergoing proxima gastric vagotomy. Eur $\mathcal{f}$ Gastroenterol Hepatol 1992; 4: 719-25. 